\title{
sciendo

\section{Energy Efficiency Obligations and Subsidies to Energy Intensive Industries in Latvia}

\author{
Kristaps LOCMELIS ${ }^{1 *}$, Uldis BARISS ${ }^{2}$, Dagnija BLUMBERGA ${ }^{3}$ \\ ${ }^{1-3}$ Institute of Energy Systems and Environment, Riga Technical University, \\ Azenes iela 12/1, Riga, LV-1048, Latvia
}

\begin{abstract}
The European Union's climate and energy policy for 2030 sets ambitious targets and will challenge current energy use patterns. At the same time, policy objectives are to maintain energy affordable for business and consumers, which means that energy and climate goals should be achieved in the most cost-effective way. There is a well-known energy efficiency gap between effectively implemented energy efficiency measures and potentially economically viable ones. The authors have made a statistical analysis of the energy costs intensity of manufacturing industries in Latvia compared to other Baltic Sea countries and have consented that the three most energy consuming manufacturing industries in Latvia show a higher share of energy costs in total production costs than in their peers over a long period of time, indicating the clearly visible possibilities for energy efficiency improvements. At the same time, Latvian energy policy provides subsidies for energy-intensive manufacturing consumers by reimbursing part of their actual electricity costs. The paper analyses the amounts of reimbursements and their breakdown by manufacturing industries, identifying the most important beneficiaries of subsidies. The authors argue that beneficiaries should direct these subsidies to further energy efficiency improvements.
\end{abstract}

Keywords - Energy efficiency; energy intensive industry; energy policy; subsidies

\section{INTRODUCTION}

Latvian industries consume approximately one fifth of total energy consumption and approximately one fourth of total electricity consumption in Latvia (Central Statistical Bureau of Latvia 2017a). The manufacturing sector in Latvia is characterized by rather high energy costs in its production value. In previous publications [1] authors benchmarked manufacturing segments according to the NACE classification of Latvia and Germany and found that, in most cases, the manufacturing industry in Latvia faced higher energy intensity compared to the same industries in Germany.

The authors proposed a hypothesis that the reason for higher vulnerability to energy costs in Latvia could arise from various factors. Firstly - higher electricity costs due to environmental charges (mandatory procurement levies in Latvia). There are studies [2], [3] that argue that these charges, which are very typical for European counties, pose risks to competitiveness of European manufacturers against international competitors. However, a similar study about Norway [4] finds that despite the relatively low electricity prices which Norwegian industries enjoy, electricityintensive industries do not solely rely on low prices but further strengthen their competitiveness through diverse strategies (including but not limited to energy efficiency measures).

\footnotetext{
* Corresponding author.

E-mail address: kristaps.locmelis@edu.rtu.lv 
Secondly, according to various studies [5]-[9] the potential for energy efficiency improvements in manufacturing industries in Latvia is clearly apparent. International studies suggest that energy efficiency measures as investments at company levels compete with the price of commodity. According to Qiu et al. [10], introduction of energy efficiency technologies in the industrial sector struggle despite their cost-efficiency. Qiu et al. explain this efficiency gap by rather high rates of returns and short payback times within which SMEs are expecting to evaluate their energy efficiency investments [10]. According to Cagno et al. [11] the existence of an energy efficiency gap between the potentially cost-effective energy efficiency improvement measures and the ones being implemented is well researched [11]. One of the very first efforts to classify various types of social and institutional energy efficiency barriers was performed by Blumstein et al. [12]. In the following years, several studies were carried out to classify barriers to energy efficiency [13]-[15]. However, Cagno et al. name the study of Sorrell et al. [16] "a crucial development" in research of energy efficiency barriers with followed modification [17], [18], which also included significant findings from Jaffe and Stavins [19] and Golove and Eto [20]. Sorrell et al. established a taxonomy of barriers to energy efficiency by categorizing them into four main theoretical frameworks: economic non-market failure, economic market failure, behavioural and organizational [18]. Cagno et al. made further improvements to the Sorrell et al. taxonomy with an addition of perspective, categorised into external and internal barriers of energy efficiency. Study [21] for the European Commission Directorate-General Energy on energy efficiency summarizes that larger organizations tend to have complex and thus more time consuming decision making processes, which hamper or delay introduction of energy efficiency measures, instead SMEs which have issues with access to internal or external capital, thereby the priorities for capital investments will typically focus on increasing output rather than energy efficiency. In a different study on adoption of energy-efficiency measures in SMEs in Germany, Fleiter et al. analysed cross-sectional data from SMEs, which participated in a German energy audit program, and concluded that access to capital is the most crucial factor in the decision to adopt energy efficiency measures, even when they are profitable. Fleiter et al. even suggest that investment subsidies or soft loans might help accelerating the implementation of energy-efficiency measures [22]. Nehler and Rasmussen conclude that energy efficiency seems to be an important issue for Swedish industrial consumers, but profitability and payback times appear to be the most important factors for investment decisions, indicating that payoff requirements are often not met based just on energy cost savings [23]. In research of substitutability between energy and capital in the manufacturing sectors, Kim and Heo conclude that industries prefer costs for energy rather than capital investments more frequently than vice versa and this asymmetric substitutability arises from much higher capital costs than energy costs in most of the countries. According to Kim and Heo, these results demonstrate that the implementation of energy efficiency measures have not been introduced despite increased energy prices [24].

Policymakers tend to tackle barriers from an external perspective, which has resulted in the development of policy instruments that lack sufficient engagement from the industry. The combination of different policy instruments that addresses the different types of external and internal energy efficiency barriers would end in better results to reach energy efficiency targets for industry [25], [26]. 


\section{Latvian Policy to TaCkle EnERgy In-EFficiency ANd Electricity Costs}

In a previous publication [27] authors analysed legal aspects of Latvian energy efficiency policy for large consumers, which requires large consumers to perform a mandatory energy audit or to introduce and maintain a certified energy management system, or supplementary energy management to environmental management system. The Law on energy efficiency imposes additional requirements to implement at least three energy efficiency measures recommended by energy audit or energy management system [28]. There is a penalty fee, if the responsible party fails to comply with the obligations [29]. This policy instrument addresses some internal barriers at the company level, that had been well-researched in various studies [30]-[34].

Another stimulating tool to promote energy efficiency policy and tackle high electricity costs is the reduction of mandatory procurement levies [35]. This Latvian energy policy, which was targeted to increase the competitiveness of the energy-intensive manufacturing industry, has an undesirable aspect, when energy efficiency measures would not be taken, is described in detail in the previous study [36]. At the end of 2017, the first eligible energy intensive manufacturing companies received reimbursement of mandatory procurement levies from mid-2015. Information about beneficiaries and reimbursement amounts are publicly available on the web site of the Ministry of Economics of Latvia [37], which allows one to make conclusions of the most energy intensive industries in Latvia and the granted aid that could be used to improve beneficiaries' energy efficiency.

\section{Most EnERgy-InTEnSIVE Segments In LATVIA AND ITS COMPARISON TO Peers in Baltic Sea Countries}

According to the Central Statistical Bureau of Latvia (2017a) [38] the top three most electricity consuming manufacturing sectors in Latvia were: manufacture of wood and wood products (NACE 16), manufacture of food products and beverages (NACE 10;11) and manufacture of other non-metallic mineral products (NACE 23), which in total account for approximately $78 \%$ of all electricity consumption in the industrial segment.

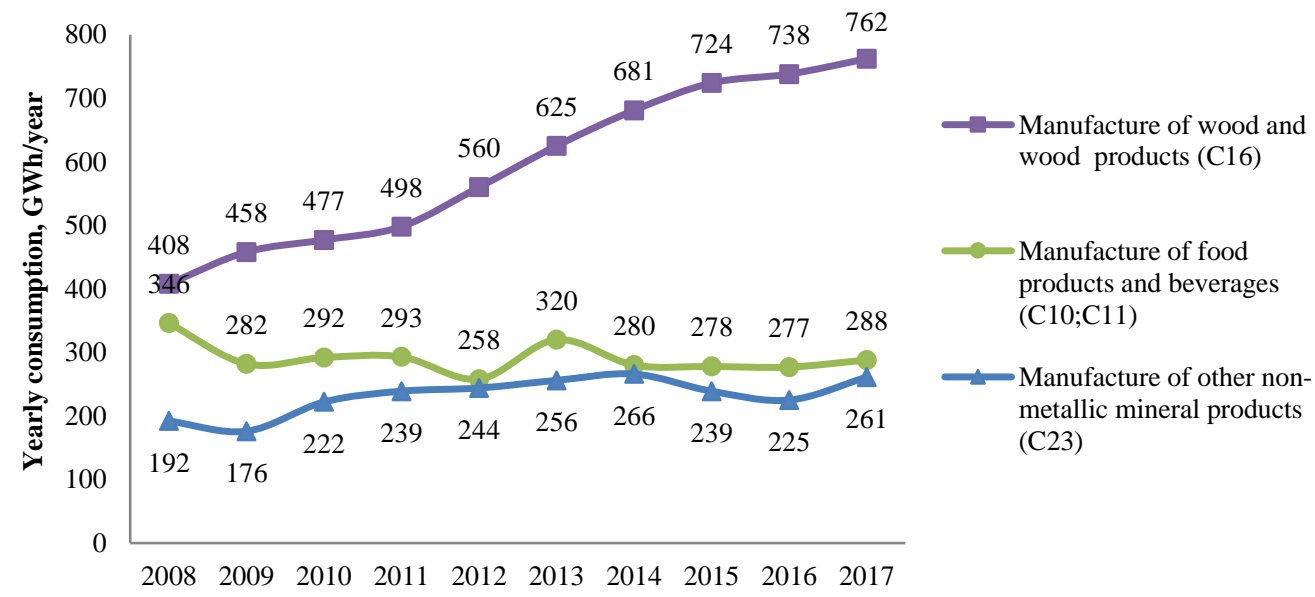

Fig. 1. Electricity consumption in top 3 most consuming manufacturing sectors in Latvia. 


\subsection{Manufacturing of Wood and Wood Products}

The wood and wood products industries are the most electricity consuming industries in Latvia and over a 10-year period have shown a steady $87 \%$ growth of electricity consumption (see Fig. 1), but are at the same time more vulnerable to increase of energy costs that their peers in other Baltic sea region countries, showing a larger share of energy costs to total production costs and with a linear trendline to increase (see Fig. 2). To analyse the energy-intensity of manufacturing sectors, Eurostat structural business statistics (SBS) are used. Energy cost to total production costs as energy intensity indicator is calculated by dividing the purchases of energy products (in million euro) [39] by total purchases of goods and services (in million euro) [40]. This indicator allows one to determine the significance of energy costs in production costs of a certain industry sector or individual enterprise. The high value of this indicator indicates the sector's or industries risk or opportunity to change energy costs, reflecting the importance of energy efficiency measures.

Energy costs to total costs as energy intensity indicator is used in reports to the European Commission [41].

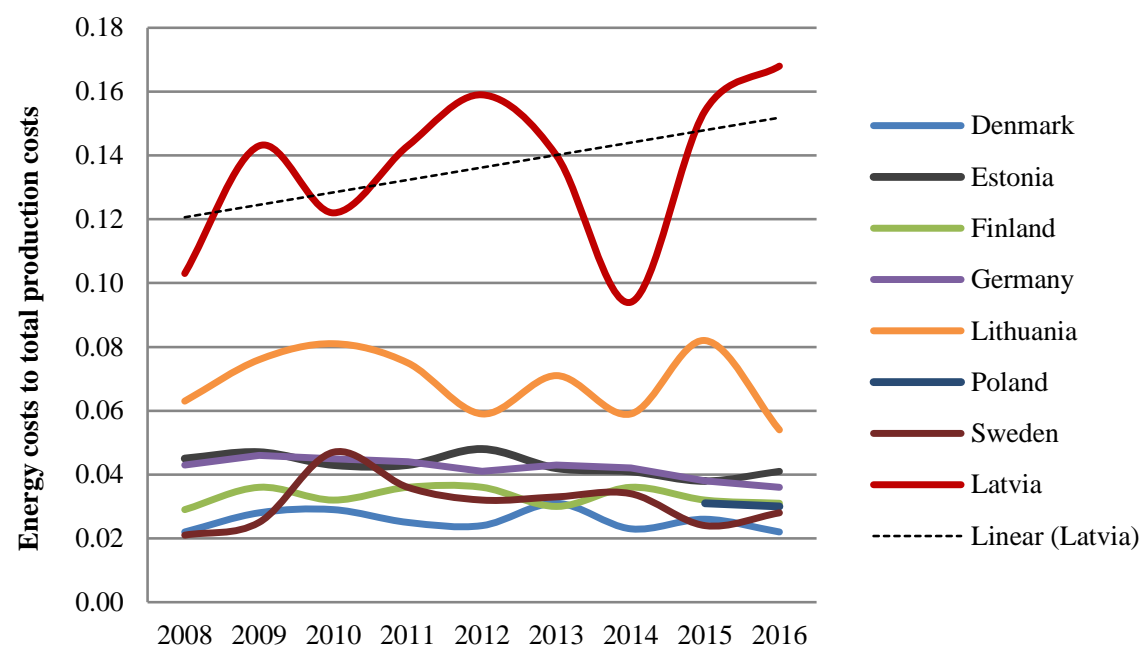

Fig. 2. Energy costs to total production costs in wood and wood products industries (Latvia and Baltic Sea region countries).

The sectoral (2-digit NACE code) data analysis of wood and wood products industries do not allow a deep analysis of the specific industries as it hides a high level of heterogeneity within the sector. In addition, as seen from the Fig. 2, in 2014 wood and wood products industries showed a deep atypical drop on energy intensity, which requires deeper subsector analyses at least at the 4-digit NACE code level.

According to Eurostat, the three most energy consuming classes of wood and wood products (4-digit NACE code) are sawmilling and planning of wood (NACE 1610), manufacture of veneer sheets and wood-based panels (NACE 1621), manufacture of other products of wood; manufacture of articles of cork, straw and plaiting materials (NACE 1629). Eurostat provides a sufficient basis of information to compare these classes across the Baltic Sea region countries. The benchmarking of Latvian manufacturing industries of sawmilling and planning of wood with neighbouring 
countries (see Fig. 3) shows that energy intensity gap narrows with a linear trend. Similar results (see Fig. 4) can be seen in manufacture of veneer sheets and wood-based panels (NACE 1621).

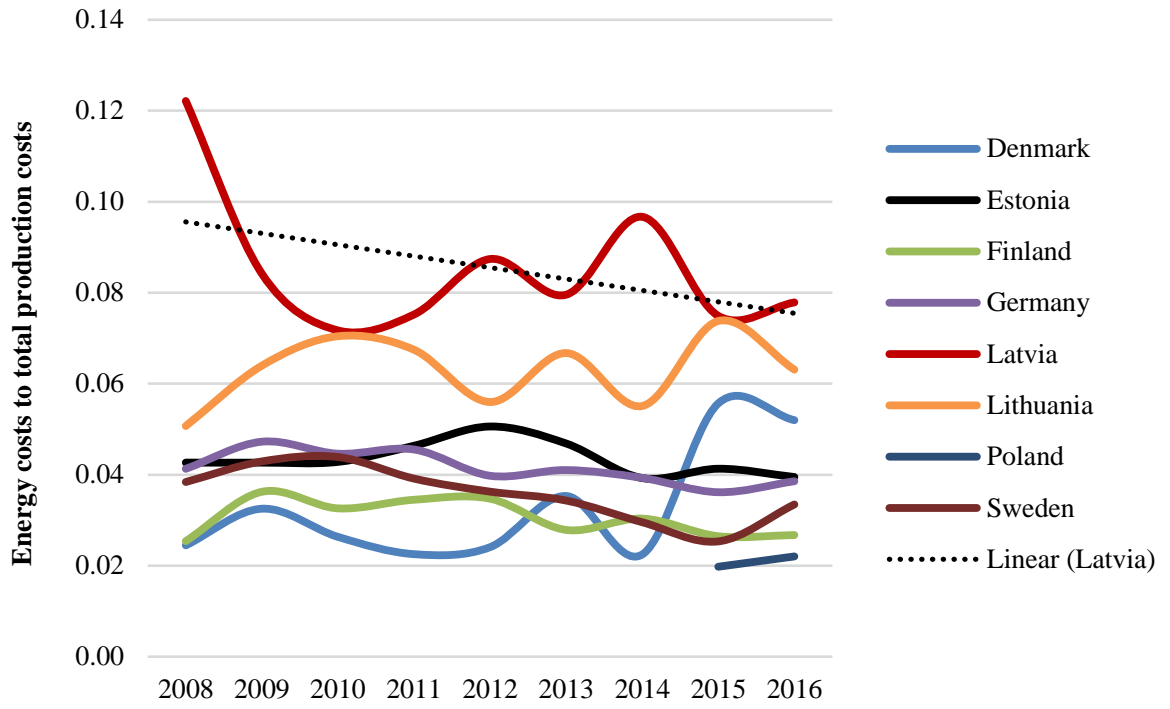

Fig. 3. Energy costs to total production costs in sawmilling and planning of wood (NACE 1610) (Latvia and Baltic Sea region countries).
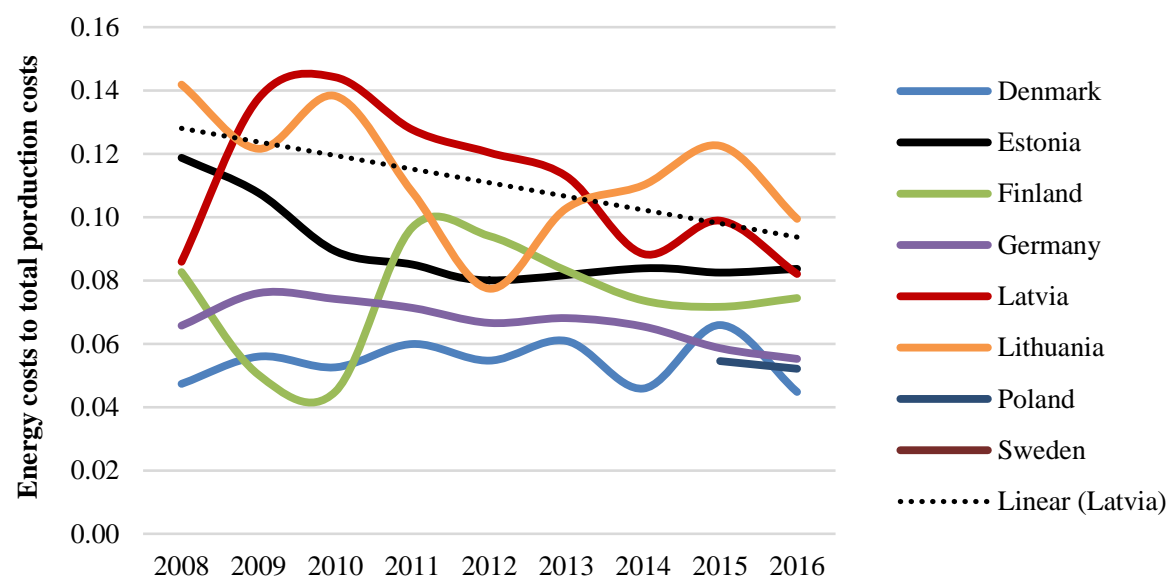

Fig. 4. Energy costs to total production costs in manufacture of veneer sheets and wood-based panels (NACE 1621) (Latvia and Baltic Sea region countries).

Different results are observed when benchmark manufacture of other products of wood; manufacture of articles of cork, straw and plaiting materials (NACE 1629) with peers in other Baltic Sea region countries. The Eurostat SBS data show a huge difference in energy intensity between Latvian companies and their peers from other Baltic Sea region countries (see Fig. 5). 
The difference is so great that the reason should be the different manufacturing technologies that lie beneath this NACE 4-digit class. The analyses of this production class show that in Latvia wood pellet producers are classified under this class, which according to Vigants et al. is considered a highly energy intensive industry [9]. Data analysis also reveals untypical results for year 2014, which is likely to be a data error and should be excluded from further sector analysis.

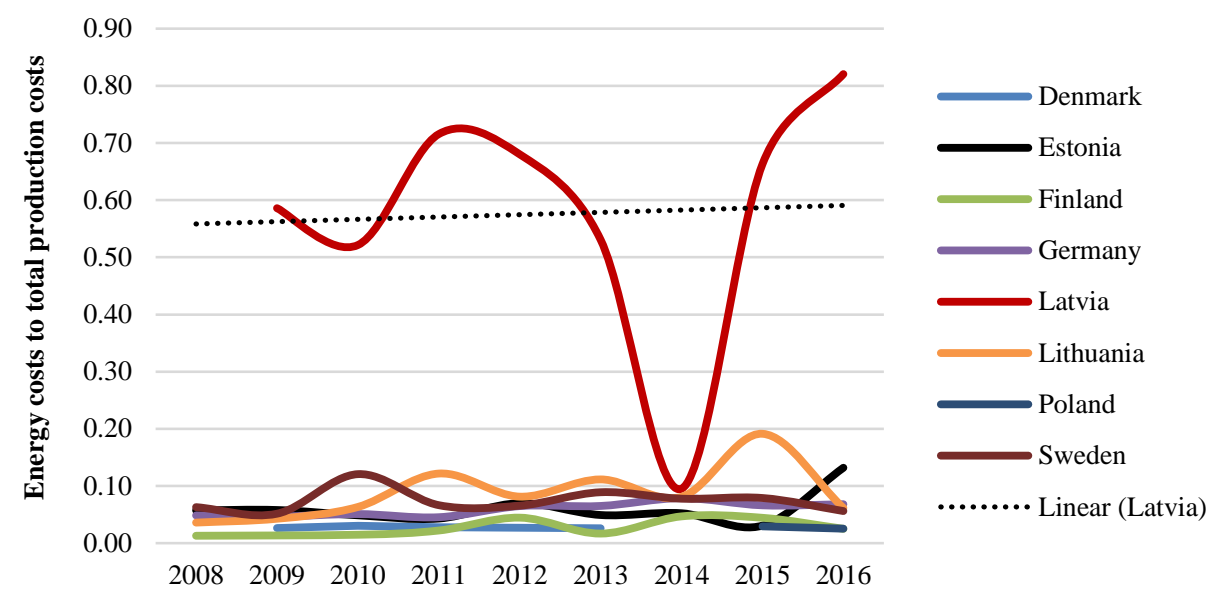

Fig. 5. Energy costs to total production costs in manufacture of other products of wood; manufacture of articles of cork, straw and plaiting materials (NACE 1629) (Latvia and Baltic Sea region countries).

Authors conclude that further analyses of the wood and wood products sector which is the top consuming manufacturing sector in Latvia, should be made on NACE 4-digit level to consider the high heterogeneity of the sector. Excluding the production of wood pellets, the rest of wood and wood production segment show linear reduction of energy costs proportionate to overall production costs closing the gap with their peers in other Baltic sea countries.

\subsection{Manufacturing of Food and Beverages Producing Industries}

Second most electricity consuming segment in Latvia is manufacturing of food and beverages, which have a rather stable electricity consumption in recent years, but with an overall consumption drop by $17 \%$ since 2008 . Food and beverage manufacturing industries statistically show lower vulnerability to energy costs (on average $6 \%$ of total production costs are related to energy costs) (see Fig. 6). 


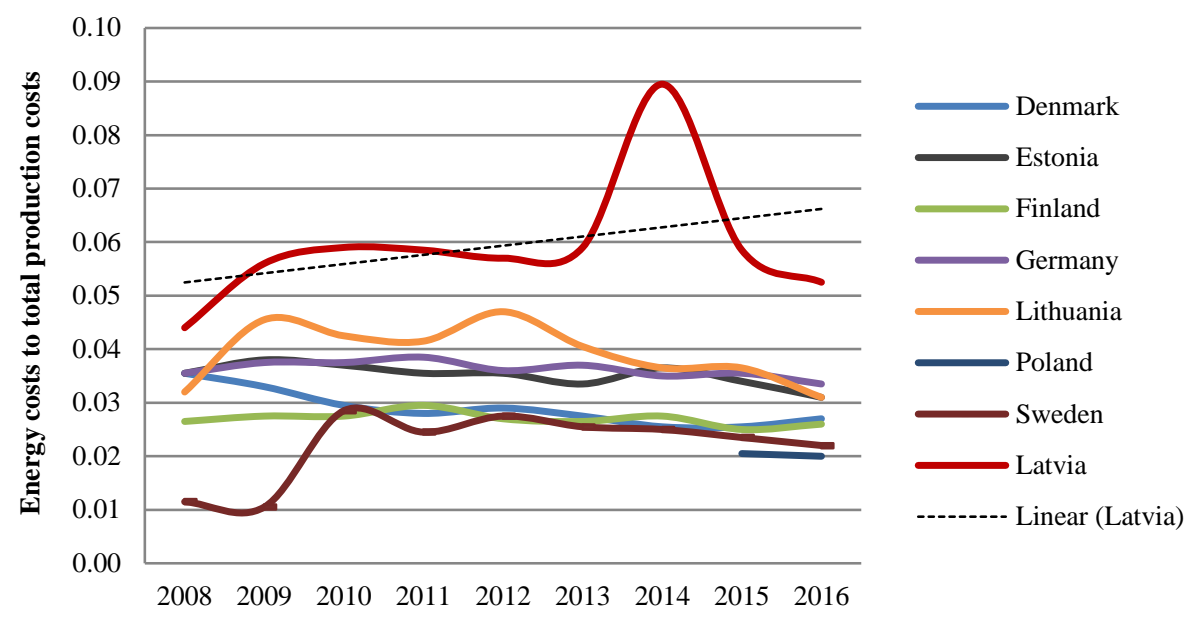

Fig. 6. Energy costs to total production costs in food and beverages producing industries (Latvia and Baltic Sea region countries).

However, the share of energy costs in the overall production costs in Latvia is reported at a higher level than other Baltic sea countries. Data analysis reveals the same untypical results for the year 2014, which is likely to be a data error and should be excluded from further sector analysis.

\subsection{Manufacturing of Non-Metallic Mineral Products}

The sectoral (2-digit NACE code) data analysis of non-metallic mineral products show that this sector records the most energy intensity in terms of energy costs to total production costs (see Fig. 7).

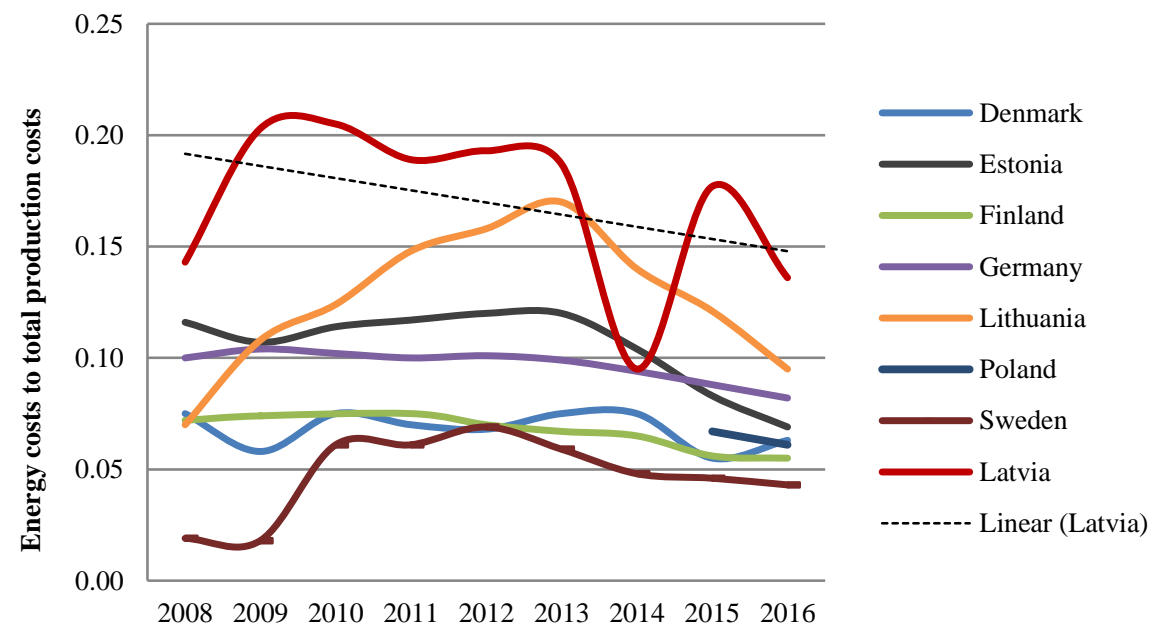

Fig. 7. Energy costs to total production costs in non-metallic minerals producing industries (Latvia and Baltic Sea region countries). 
However, this sector consists of two subsegments that has high impact on energy consumption, but have different energy intensity - manufacture of glass fibres (NACE 4-digit code 2314) and manufacture of cement (NACE 4-digit code 2351) and the sectoral mix of the two major manufactory classes makes it difficult to make an in-deep analysis of specific industries. A detailed analysis on the industry level (NACE 4-digit subsegments) is hampered by the fact that Eurostat does not providing detailed data for each of the subsegments (due to classified information). Authors chose to compare the Latvian non-metallic sector intensity (NACE 2-digit code 23) with the corresponding subsegments of Germany (both subsegments NACE 4-digit code 2314 and 2351) and manufacturing of glass fibres in other Baltic sea countries (NACE 4-digit code 2314). Results show (see. Fig. 8) that the Latvian energy intensity indicator, which consists mainly of both subsegments, is below the indicator of cement production in Germany and above the corresponding indicator of fiberglass production in other Baltic Sea region countries.

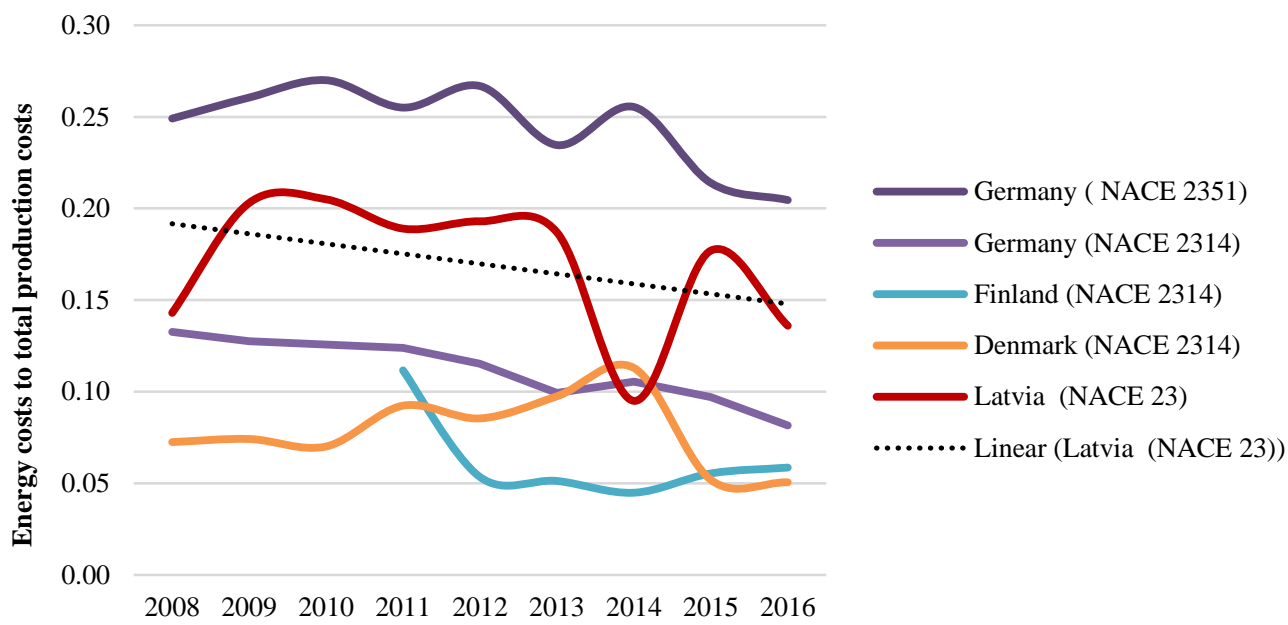

Fig. 8. Energy costs to total production costs in non-metallic minerals producing industries in Latvia (NACE 23), manufacture of cement in Germany (NACE 2351) and manufacture of fibre glass (NACE 2314) in Baltic Sea region countries.

Data analysis reveals the same untypical results for the year 2014, which is likely to be a data error and should be excluded from further sector analysis.

\section{ENERGY INTENSIVE INDUSTRIES AND REIMBURSEMENT OF MANDATORY Procurement Levies}

According to the information provided on the website of the Ministry of Economics of Latvia [37], from July 2015 until December 2018, there are 34 positive decisions regarding reimbursement of mandatory procurement levies with the total sum of 7.84 million EUR (see Table 1). 
TABLE 1. BENEFICIARIES OF REIMBURSEMENT OF MANDATORY PROCUREMENT LEVIES

\begin{tabular}{|c|c|c|c|c|}
\hline \multirow{2}{*}{$\begin{array}{l}\text { Beneficiaries } \\
\text { NACE Rev. } 2\end{array}$} & \multicolumn{4}{|c|}{ Reimbursement of mandatory procurement levies, EUR } \\
\hline & 2015 & 2016 & 2017 & SUM (2015-2017) \\
\hline 1610 & 105833.97 & 346312.41 & - & 452146.38 \\
\hline 1621 & - & 268550.00 & 379883.79 & 648433.79 \\
\hline 1623 & 46887.56 & 103381.22 & - & 150268.78 \\
\hline 1629 & 834868.97 & 1561489.75 & 90078.85 & 2786437.57 \\
\hline 2222 & 10800.53 & 26252.49 & - & 37053.02 \\
\hline 2314 & 333030.67 & 691387.62 & - & 1024418.29 \\
\hline 2351 & 525192.87 & 774589.82 & 1367593.43 & 2667376.12 \\
\hline 2410 & - & 29606.61 & - & 29606.61 \\
\hline 2451 & 12880.66 & 31593.68 & - & 44474.34 \\
\hline TOTAL & 1869495.23 & 3833163.60 & 2137556.07 & 7840214.90 \\
\hline
\end{tabular}

It should be noted than this is not a complete list of beneficiaries as the regulation provides that reimbursement could be claimed later in time and it takes time to process applications. So far there is very limited list of manufacturing segment that are eligible for reimbursement:

- Wood and wood products industries (NACE 4-digit 1610, 1621, 1623, 1629);

- Non-metallic minerals producing industries (NACE 4-digit 2314, 2351);

- Production of basic metals (NACE 4-digit 2410, 2451);

- Manufacture of plastic products (NACE 4-digit 2222).

Approximately $51.5 \%$ of 7.8-million-euro reimbursement of mandatory procurement levies were received by the wood and wood products industries, $47 \%$ - by non-metallic minerals producing industries and only $0.5 \%$ of 7.8 million euros were received by other manufacturing industries (see Fig. 9). The largest volume was individually received by a cement manufacturing company, however large reimbursements were received for the manufacture of other products of wood, manufacture of articles of cork, straw and plaiting. Beneficiaries from this segment are those operating wood pellet manufacturing. 


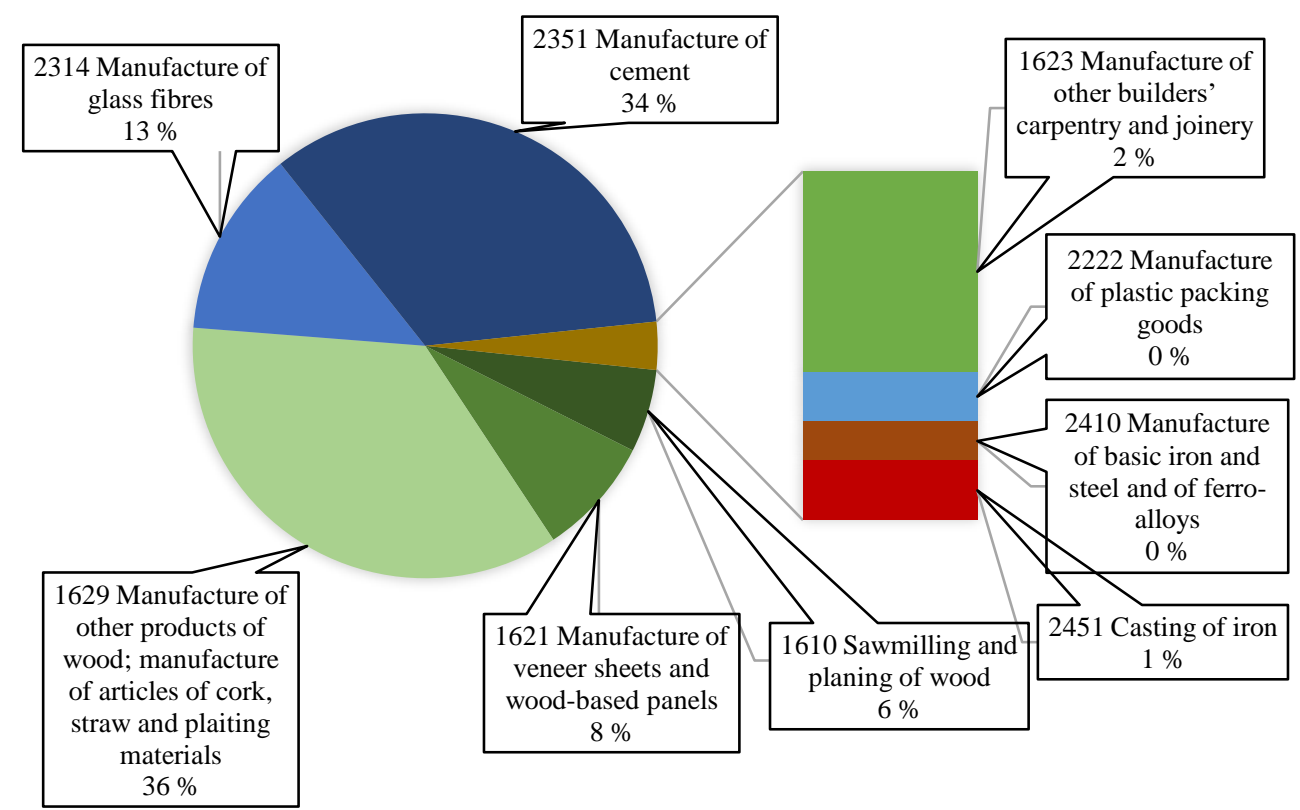

Fig. 9. Breakdown of reimbursement of mandatory procurement levies between industrial segments in Latvia (2015-2017).

\section{Conclusions}

Statistical data of Latvian manufacturing industries show rather high risks on energy costs, as the share of energy costs to total production costs in Latvia is significantly higher than to its peers in other Baltic Sea countries. Latvia's and the European Union's [35], [42] energy policy for energy intensive industries provides an incentive to reimburse a part of electricity costs in the form of mandatory procurement levies. However, the rather long delay between the period when electricity costs occurred and time of reimbursement, as well as rather the cumbersome procedure, allows to conclude that manufacturing industries could not fully rely on the reimbursement of mandatory procurement levies and most likely they did not reduce the price of production. From that perspective, assuming that higher energy intensity could affect the long-term competitiveness of industry, policy implementation, in which the industry could not fully rely on a permanent reduction in electricity prices in the long run, could serve as an additional incentive to invest in energy efficiency measures, as it could ensure long-term competitiveness relying on internal resources and processes, rather than just paid out to the shareholders as windfall profit, but this hypothesis should be researched further.

\section{ACKNOWLEDGEMENT}

This research is funded by the Ministry of Economics of the Republic of Latvia, project "The pathway to energy efficient future for Latvia (EnergyPath)", project No. VPP-EM-EE-2018/1-0006. 


\section{REFERENCES}

[1] Locmelis K., Bariss U., Blumberga D. Latvian energy policy on energy intensive industries. Energy Procedia 2017:113:362-368. doi:10.1016/j.egypro.2017.04.008

[2] Lutz C. et al. Electricity Costs of Energy Intensive industries. An International Comparison. Technical report, 2015. doi:10.13140/RG.2.1.2442.9286

[3] Drabik E., Koper M., Egenhofer C., Rizos V., Afanador A., Simonelli F., Hähl T., Renda A., Zarra A., Faure A., Bons M., Schmitt W. Composition and drivers of energy prices and costs: Case studies in selected energy intensive industries, 2018: final report. Publications Office of the EU, 2018.

[4] Grave K., Bourgault C., Breitschopf B. Electricity costs of energy-intensive industries in Norway - a comparison with energy-intensive industries in selected countries (2016) [Online]. [Accessed 14.03.2019]. Available: https://www.energinorge.no/contentassets/525e77b1feff4203a94ef6d1f94cfd03/electricity-costs-of-energy-intensiveindustries-in-norway.pdf

[5] Kursisa A., Gleizde L. Energy consumption and its reduction potential in Latvian industry sectors. Civil Engineering International Scientific Conference Proceedings 2013:363-371.

[6] Blumberga D., Vigants H., Cilinskis E., Vitolins V., Borisova I., Khabdullin A., Khabdullin A., Khabdullina Z., Khabdullina G., Veidenbergs I. Energy Efficiency and Energy Management Nexus. Energy Procedia 2016:95:71-75. doi:10.1016/j.egypro.2016.09.023

[7] Zogla L. Methodology for modelling Energy Efficiency policy instruments in industrial sector. Summary of PhD thesis. Riga: Riga Technical University, 2014.

[8] Ozolina L., Rosa M. A review of energy efficiency policy and measures for industries in Latvia. Management of Environmental Quality 2012:23(5):517-526. doi:10.1108/14777831211255097

[9] Vigants H., Blumberga D., Veidenbergs I. Demand side management in pellet production: internal and external factors. Environmental and Climate Technologies 2014:14(1):30-35. doi:10.1515/rtuect-2014-0011

[10] Qiu Y., Wang Y., Wang J. Implied discount rate and payback threshold of energy efficiency investment in the industrial sector. Applied Economics 2015:47(21):2218-2233. doi:10.1080/00036846.2015.1005820

[11] Cagno E., Worrell E., Trianni A., Pugliese G. A novel approach for barriers to industrial energy efficiency. Renewable and Sustainable Energy Reviews 2013:19:290-308. doi:10.1016/j.rser.2012.11.007

[12] Blumstein C., Krieg B., Schipper L., York C. Overcoming social and Institutional barriers to energy conservation. Energy 1980:5(4):355-371. doi:10.1016/0360-5442(80)90036-5

[13] Painuly J. P., Reddy B. S. Electricity Conservation Programs: Barriers to Their Implementation. Energy Sources 1996:18(3):257-267. doi:10.1080/00908319608908765

[14] Weber L. Some reflections on barriers to the efficient use of energy. Energy Policy 1997:25(10):833-835. doi:10.1016/S0301-4215(97)00084-0

[15] Almeida A. T. D., Fonseca P., Falkner H., Bertoldi P. Market transformation of energy-efficient motor technologies in the EU. Energy Policy 2003:31(6):563-575. doi:10.1016/S0301-4215(02)00100-3

[16] Sorrell S., et al. Reducing barriers to energy efficiency in public and private organisations. Brighton, 2000.

[17] Sorrell S., Malley E. O., Schleich J., Scott S. The economics of Energy Efficiency. Cheltenham: Edward Elgar Publishing, 2004.

[18] Sorrell S., Mallett A., Nye S. Barriers to industrial energy efficiency: A literature review. Brighton: 2010.

[19] Jaffe A. B., Stavins R. N. The energy-efficiency gap. What does it mean? Energy Policy 1994:22(10):804-810. doi:10.1016/0301-4215(94)90138-4

[20] Golove W. H., Eto J. H. Market Barriers to Energy Efficiency: A Critical Reappraisal of the Rationale for Public Policies to Promote Energy Efficiency. Technical report, 1996. doi:10.2172/270751

[21] Study on energy efficiency and energy saving potential in industry and possible policy mechanisms [Online]. [Accessed 10.03.2019]. Available: https://ec.europa.eu/energy/sites/ener/files/documents/151201\%20DG\%20ENER\%20Industrial\%20EE\%20study\%20 -\%20final\%20report_clean_stc.pdf

[22] Fleiter T., Schleich J., Ravivanpong P. Adoption of energy-efficiency measures in SMEs - An empirical analysis based on energy audit data from Germany. Energy Policy 2012:51:863-875. doi:10.1016/j.enpol.2012.09.041

[23] Nehler T., Rasmussen J. How do firms consider non-energy benefits? Empirical findings on energy-efficiency investments in Swedish industry. Journal of Cleaner Production 2016:113:472-482. doi:10.1016/j.jclepro.2015.11.070

[24] Kim J., Heo E. Asymmetric substitutability between energy and capital: Evidence from the manufacturing sectors in 10 OECD countries. Energy Economics 2013:40:81-89. doi:10.1016/j.eneco.2013.06.014

[25] Tanaka K. Review of policies and measures for energy efficiency in industry sector. Energy Policy 2011:39(10):6532-6550. doi:10.1016/j.enpol.2011.07.058

[26] Bosseboeuf D., et al. Energy Efficiency Policies in the EU. Lessons from the Odyssee-Mure Project, 2013 [Online]. [Accessed 02.02.2019]. Available: http://www.odyssee-mure.eu/publications/br/MURE-Overall-Policy-Brochure.pdf 
[27] Locmelis K., Blumberga D., Bariss U. Energy efficiency in large industrial plants. Legislative aspects. Energy Procedia 2018:147:202-206. doi:10.1016/j.egypro.2018.07.058

[28] Energy Efficiency Law [Online]. [Accessed 09.02.2019]. Available: https://likumi.lv/ta/en/en/id/280932-energy-efficiency-law

[29] Cabinet of Ministers. Regulation on the amount of the energy efficiency fee and the procedure for its calculation, application, payment and control. Latvijas Vestnesis 76(5903). (in Latvian)

[30] Thollander P., Ottosson M. An energy-efficient Swedish pulp and paper industry: exploring barriers to and driving forces for cost-effective energy efficiency investments. Energy Efficiency 2008:1(1):21-34. doi:10.1007/s12053-0079001-7

[31] Stenqvist C., Nilsson L. J. Process and impact evaluation of PFE - a Swedish tax rebate program for industrial energy efficiency. Paper presented at 9th ECEEE summer study Act! Innovate! Deliver! Reducing energy demand sustainably, 2009.

[32] Stenqvist C., Nilsson L. J. Energy efficiency in energy-intensive industries - an evaluation of the Swedish voluntary agreement PFE. Energy Efficiency 2012:5(2):225-241. doi:10.1007/s12053-011-9131-9

[33] Beihmanis K., Rosa M. Energy Management System Implementation in Latvian Municipalities: From Theory to Practice. Energy Procedia 2016:95:66-70. doi:10.1016/j.egypro.2016.09.018

[34] Worrel E. Barriers to energy efficiency: International case studies on successful barrier removal. Working paper 14/2011. United nations Industrial Development Organization, 2011.

[35] Cabinet of Ministers. The order on how energy efficiency processing production industries obtain rights to decreased participation in the payment of mandatory procurement component. Latvijas Vestnesis 149(5467). (in Latvian)

[36] Locmelis K., Blumberga A., Bariss U., Blumberga D. Energy policy for energy intensive manufacturing companies and its impact on energy efficiency improvements. System dynamics approach. Energy Procedia 2017:128:10-16. doi:10.1016/j.egypro.2017.09.005

[37] Ministry of Economics of Latvia. Information of the published decisions regarding the support to energy efficiency processing production industries, 2019. [Online]. [Accessed 12.03.2019]. Available: https://www.em.gov.lv/files/attachments/Lemumi_OIKsamEnergoietilpi_MK395_12032019.xlsx (in Latvian)

[38] Central Statistical Bureau of Latvia. Energy balance, in natural units (NACE Rev.2). Table ENG010 (2017 annual data) [Online]. [Accessed 13.03.2019]. Available: https://www.csb.gov.lv/lv/statistika/db

[39] Statistical office of the European Union. Annual detailed enterprise statistics for industry. Purchases of energy products (V20110) [Online]. [Accessed 13.03.2019]. Available: https://ec.europa.eu/eurostat/data/database

[40] Statistical office of the European Union. Annual detailed enterprise statistics for industry. Total purchases of goods and services (V13110) [Online]. [Accessed 13.03.2019]. Available: https://ec.europa.eu/eurostat/data/database

[41] European Commission. Energy prices and costs in Europe. Report from the Commission to the European Parliament, the Council, the European economic and social committee and the Committee of the regions, 2016. [Online]. [Accessed 28.12.2018]. Available: https://eur-lex.europa.eu/resource.html?uri=cellar:69cbbdb1-b708-11e6-9e3c01aa75ed71a1.0001.02/DOC_9\&format=PDF

[42] European Commission. Communication from the Commission — Guidelines on State aid for environmental protection and energy 2014-2020. Official Journal of the European Union 2014:57:1-55. 